\title{
Studies on the Biochemical Basis of the Low Maximum Temperature in a Psychrophilic Gryptococcus
}

\author{
BY P-O. HAGEN* AND A. H. ROSE† \\ Microbiology Laboratory, Heriot-Watt College, Edinburgh, Scotland
}

(Received 29 April 1961)

\section{SUMMARY}

A psychrophilic species of Cryptococcus, freshly inoculated cultures of which grew well in a glucose + salts + vitamins medium at $16^{\circ}$ but not at all at $30^{\circ}$, was induced to grow rapidly for a period at $30^{\circ}$ by previous incubation at $16^{\circ}$. A study was made of certain aspects of the biochemical composition of the cryptococcus in cultures maintained at $16^{\circ}$ as compared with that in cultures transferred from $16^{\circ}$ to $30^{\circ}$, in order to obtain information about the biochemical basis of the low maximum growth temperature for this organism. With the cryptococcus transferred from $16^{\circ}$ to $30^{\circ}$, there was rapid utilization of intracellular reserves of total amino acids and total oxo acids. Exogenous sources of amino acids were unable to replenish the intracellular amino acid pool in the cryptococeus incubated at $30^{\circ}$. However, addition of $\alpha$-oxoglutarate, citrate, or DL-isocitrate to cultures transferred to $30^{\circ}$ after $120 \mathrm{hr}$. at $16^{\circ}$ enabled the cryptococcus to continue to grow at the higher temperature; stimulation of growth at $30^{\circ}$ was most marked in cultures supplemented with $\alpha$-oxoglutarate. Other tricarboxylic acid cycle and related intermediates (pyruvate, acetate, succinate, fumarate, L-malate, oxaloacetate) had no growth-promoting effect. Stimulation of growth at $30^{\circ}$ in the presence of $\alpha$-oxoglutarate was obtained only in cultures which had been incubated for 2-4 days at $16^{\circ}$, indicating the existence of other temperature-sensitive metabolic processes in addition to those concerned in $\alpha$-oxoglutarate synthesis.

\section{INTRODUCTION}

The existence of psychrophilic strains of micro-organisms has been recognized for many years, but the biochemical basis of the psychrophilic habit is still unknown. Obligate psychrophils are distinguished from mesophils by their ability to grow well at temperatures just above $0^{\circ}$ and by their inability to grow at temperatures above about $30^{\circ}$. Both of these characteristics are presumably reflexions of the properties of certain enzymes in these organisms, but little if anything is known about these enzymes. The temperature coefficient of oxidation of several substrates has, however, been shown to be less for psychrophils than for mesophils (Brown, 1957; Ingraham \& Bailey, 1959) which suggests that certain of the enzymes in psychrophils are less affected by a decrease in temperature than are the corresponding enzymes in

* Present address, Microbiology Section, Division of Applied Biology, National Research Council, Ottawa, Canada.

† Present address, Bacteriology Department, University of Durham, King's College, Newcastleupon-Tyne. 
mesophils. Attempts have been made to explain the inability of obligate psychrophils to grow at higher temperatures by postulating the existence of exceptionally thermolabile enzymes. Studies on the effect of temperature on the activities of a number of enzymes in cell-free extracts of certain psychrophilic micro-organisms have so far failed to reveal the existence of such thermolabile enzymes (Ingraham \& Bailey, 1959).

In a previous paper (Hagen \& Rose, 1961) it was reported that a psychrophilic species of the yeast Cryptococcus which did not grow in freshly-inoculated cultures at $30^{\circ}$ was induced to grow at this temperature when the cultures were incubated initially at $16^{\circ}$. Although this phenomenon was first reported with a newly described species of Cryptococcus, it has since been observed with several other psychrophilic yeasts (unpublished observations). This phenomenon appeared to provide a new and more rigorous method for studying the biochemical basis of the low maximum temperature in obligate psychrophils for, by comparing the biochemical activities of yeast in cultures that had been transferred from $16^{\circ}$ to $30^{\circ}$ with yeast from cultures that had been maintained at $16^{\circ}$, it might be possible to discover differences that would indicate a biochemical basis for the temperature-sensitive habit. The present paper describes experiments which were carried out with the psychrophilic cryptococcus with the object of discovering such differences.

\section{METHODS}

\section{Culture methods}

Organism. The strain of Cryptococcus used in this study was described by Hagen \& Rose (1961). It was maintained on slopes of malt wort agar: $10 \%(w / v)$ spray-dried malt extract ('Muntona', Munton \& Fison Ltd., Stowmarket, Suffolk) $+2 \%$ (w/v) agar. Slope cultures were grown at $16^{\circ}$ and stored at $3^{\circ}$.

Medium. The basal medium ( $\mathrm{pH} 4.5$ ) used was that described by Rose \& Nickerson (1956). The concentration of glucose in this medium was occasionally decreased from 2 to $1 \%(\mathrm{w} / \mathrm{v})$; in certain experiments the glucose was replaced by some other carbon source at $0.92 \%(\mathrm{w} / \mathrm{v})$. Solutions of various substances were also added to these media as described later; these solutions were adjusted to $\mathrm{pH} 4.5$ and sterilized separately by autoclaving momentarily at $10 \mathrm{lb}$./sq.in. or by Seitz filtration.

Experimental cultures. Cultures of the cryptococcus were grown in Samco tubes covered with anodized aluminium caps as described by Northam \& Norris (1951). Portions of medium $(6 \mathrm{ml}$.) were sterilized and inoculated as described previously (Hagen \& Rose, 1961). Growth in the Samco tubes was measured turbidimetrically by a Hilger 'Spekker' absorptiometer (model H. 760) 'with neutral green-grey filters and a water blank. Turbidity readings were related to the number of cryptococci $/ \mathrm{ml}$. by a calibration curve. Large crops of organism for estimations of total intracellular amino acids and oxo acids were obtained by pooling large numbers of these $6 \mathrm{ml}$. cultures.

\section{Analytical methods}

Nucleic acids. The content of deoxyribonucleic acid (DNA), ribonucleic acid (RNA) and acid-soluble ultraviolet (u.v.)-absorbing substances in portions $\left(30.0 \times 10^{7}\right.$ organisms) of the cryptococcus which had been washed twice with $\mathrm{M} / 15 \mathrm{KH}_{2} \mathrm{PO}_{4}$ (pH 4.5) were estimated by the procedures described by Ahmad, Rose \& Garg (1961). 
Protein in the residue remaining after nucleic acids and related substances had been extracted from the cryptococcus was determined by the micro-Kjeldahl technique (Markham, 1942) with a mercuric oxide catalyst (Miller \& Houghton, 1945).

Intracellular amino acid pools. Water-soluble ninhydrin-positive substances were extracted from the cryptococcus by suspending $60.0 \times 10^{7}$ washed organisms in $10 \mathrm{ml}$. water and holding the suspension for $20 \mathrm{~min}$. in an oil bath at $140^{\circ}-150^{\circ}$. On cooling, the supernatant fluid (3-4 ml.) was removed from the cell debris by centrifugation; after being supplemented with washings $(2.0 \mathrm{ml}$.) from the cell debris, the volume of extract was made up to $10.0 \mathrm{ml}$. with water. These extracts were then assayed for total ninhydrin-positive substances by a modification of the method described by Smith \& Agiza (1957) (Mr A. L. S. Munro; unpublished observations). Samples $(1.0 \mathrm{ml}$.) of extract were added to $1.0 \mathrm{ml}$. citrate buffer $(0.05 \mathrm{M}, \mathrm{pH} 5.0)$ and $1.0 \mathrm{ml}$. ninhydrin solution $(5.50 \mathrm{mg} . / \mathrm{ml}$. in citrate buffer) added to each tube. The tubes were then placed in a boiling water bath and $1.0 \mathrm{ml}$. stannous chloride solution $(0.2 \%, w / v$, in citrate buffer) added to each tube. The tubes were kept in the boiling water bath for $15 \mathrm{~min}$., then removed to a beaker of crushed ice and allowed to cool in the dark. Rapid cooling in the dark was essential in order to obtain consistent results. The contents of each tube were then made up to $10.0 \mathrm{ml}$. with ice-cold saturated $\mathrm{NaCl}$ solution, and this was followed by the addition of $5.0 \mathrm{ml}$. ice-cold $n$-butanol. Each tube was then stoppered and vigorously shaken, the blue colour being taken up in the butanol layer which was removed, and the optical density of the butanol extract measured at $570 \mathrm{~m} \mu$ in a Unicam S.P. 600 spectrophotometer in $1 \mathrm{~cm}$. glass cells; blanks were prepared by using $1.0 \mathrm{ml}$. water instead of $1.0 \mathrm{ml}$. extract. Optical density readings were related to $\mu \mathrm{g}$. amino group $\left(\mathrm{NH}_{2}\right) / \mathrm{ml}$. by a standard curve prepared by using purified glycine. The results, which are taken as a measure of the intracellular amino acid pool in the cryptococcus, are expressed as $\mu \mathrm{g}$. $\mathrm{NH}_{2} / 60.0 \times 10^{7}$ organisms.

Intracellular oxo acid pools. Extracts for the determination of total oxo acids in the cryptococcus were prepared in the same way as for the determination of amino acid pools, except that $600 \times 10^{7}$ organisms were used. Recoveries of $98 \cdot 6-99.2 \%$ were obtained when $\alpha$-oxoglutaric acid and pyruvic acid were subjected to this extraction procedure. The total oxo acid contents of the extracts $(10.0 \mathrm{ml}$.) were determined by the 2:4-dinitrophenylhydrazine method described by Friedemann \& Haugen (1948). Optical density readings were related to the oxo acid content by a standard curve prepared by using purified $\alpha$-oxoglutaric acid. Results are expressed as $\mu$ g. $\alpha$-oxoglutaric acid equivalent $/ 60.0 \times 10^{7}$ organisms.

Chromatography. Amino acid extracts $(8.0 \mathrm{ml}$.) from cryptococci were evaporated on a boiling water bath to $0.5 \mathrm{ml}$., and examined chromatographically on Whatman No. 1 paper. A solvent consisting of $n$-butanol + glacial acetic acid + water $(4+1+5$ by vol.) was used, the butanol layer acting as the mobile phase. Extracts were applied on the paper as spots (about $2 \mu \mathrm{l}$.), larger amounts being applied by successive application of $2 \mu \mathrm{l}$. drops. A measured sample of extract containing $10 \cdot 0 \mu \mathrm{g}$. $\mathrm{NH}_{2}$ was applied on each spot; controls containing mixtures of known amino acids were run with each chromatogram. Papers were irrigated for 40-44 hr. at room temperature (about $18-20^{\circ}$ ) and, when the solvent front had descended off the paper, they were removed and dried with a hair dryer. The papers were developed by spraying with a solution of ninhydrin $(0 \cdot 1 \%, \mathrm{w} / \mathrm{v})$ in $n$-butanol. 
For chromatographic examination of the oxo acids, the sodium carbonate solution of the oxo acid 2:4-dinitrophenylhydrazones obtained during the quantitative estimation of the total oxo acids (Friedemann \& Haugen, 1943) was adjusted to about pH 2.0 using conc. $\mathrm{HCl}$, and extracted with ethyl acetate $(5.0 \mathrm{ml}$.). This ethyl acetate extract was then evaporated to dryness in a stream of air at room temperature, and the residue taken up in $0.2 \mathrm{ml}$. ethyl acetate. This solution was then spotted on Whatman No. 4 paper, and the oxo acid 2:4-dinitrophenylhydrazones separated by descending chromatography using a solvent consisting of $n$-butanol + water + ethanol $(95 \%, v / v)(5+4+1$ by vol.), the butanol being used as the mobile phase (Meister \& Abendschein, 1956). Papers were irrigated for 10-14 hr. at room temperature and, after drying with a hair dryer, were examined under u.v. radiation; occasionally, they were also sprayed with a solution of $\mathrm{NaOH}(1.5 \mathrm{~N})$ which caused the oxo acid 2:4dinitrophenyl hydrazones to appear as brown spots on the paper. Controls of $\alpha$-oxoglutaric, oxaloacetic and pyruvic acids were run with each chromatogram.

\section{RESULTS}

Preliminary experiments did not reveal any marked differences in the contents of DNA, RNA, acid-soluble ultraviolet-absorbing substances or protein in the cryptococcus grown at $16^{\circ}$ compared with cryptococci from cultures of the same age which had been transferred to $30^{\circ}$ after $120 \mathrm{hr}$. at $16^{\circ}$. But, when the amounts of total intracellular amino acids in the cryptococci grown under each of these conditions were compared, then certain major differences were observed.

\section{Effect of change in incubation temperature on the size of the intracellular amino acid pool}

The data in Fig. 1 show the effect of varying the incubation temperature between $16^{\circ}$ and $30^{\circ}$ on growth of, and the size of the intracellular amino acid pool in, the cryptococcus. Transferring cultures to $30^{\circ}$ after $72 \mathrm{hr}$. at $16^{\circ}$ accelerated growth of the yeast for approximately $120 \mathrm{hr}$., after which time there was no further increase in the turbidity of cultures (Hagen \& Rose, 1961). This temporary acceleration in the growth rate was accompanied by a rapid decline in the amount of total intracellular amino acids in the cryptococcus as compared with yeast maintained at $16^{\circ}$. When cultures which had been transferred from $16^{\circ}$ to $30^{\circ}$ were returned to $16^{\circ}$ after $144 \mathrm{hr}$. at the higher temperature, the cryptococcus again started to grow. This second period of incubation at $16^{\circ}$ coincided with an increase in the size of the intracellular amino acid pool which, however; was again depleted when these cultures were transferred for a second time to $30^{\circ}$ after $144 \mathrm{hr}$. incubation at $16^{\circ}$.

This fall in the content of intracellular amino acids in cryptococci transferred from $16^{\circ}$ to $30^{\circ}$ was shown not to be the result of excretion of ninhydrin-positive substances. Portions $(10 \mathrm{ml}$.) of cell-free spent medium from $168 \mathrm{hr}$. and $216 \mathrm{hr}$. cultures that had been maintained at $16^{\circ}$ or had been transferred from $16^{\circ}$ to $30^{\circ}$ after $120 \mathrm{hr}$. were made alkaline with $2 \mathrm{~N} \mathrm{NaOH}$ and heated for $30 \mathrm{~min}$. in a boiling water bath to liberate ammonia. The solutions were neutralized and concentrated on a boiling water bath to a volume of $2 \mathrm{ml}$. These concentrates were then examined chromatographically for the presence of ninhydrin-positive substances. Each of the cell-free media showed a faint trace of only one ninhydrin-positive substance which migrated 
identically with alanine. There was, however, no detectable difference in the intensity of this spot in chromatograms of concentrates of spent media from cultures that had been maintained at $16^{\circ}$ as compared with cultures that had been transferred from $16^{\circ}$ to $30^{\circ}$.

Chromatographic examination of concentrates prepared from cell extracts revealed that, when cultures were transferred from $16^{\circ}$ to $30^{\circ}$, there was a rapid decline in the amount of glutamic acid in the intracellular amino acid pool; in chromatograms of extracts from cryptococci which had stopped dividing at $30^{\circ}$, the glutamic acid spot was no longer visible. This amino acid reappeared in chromatograms of extracts of the



Fig. 1. Growth of cryptococci (-), and size of the intracellular amino acid pool (- . - - ), following the transfer of cultures from $16^{\circ}(O)$ to $30^{\circ}(O)$ after $72 \mathrm{hr}$., followed by a return to $16^{\circ}(\triangle)$ after a further $144 \mathrm{hr}$. The effect of a second transfer from $16^{\circ}$ to $30^{\circ}$ is also shown $(x)$.

cryptococcus from cultures that had been returned to $16^{\circ}$ after a period at $30^{\circ}$, only to disappear again when the cultures were re-incubated at $30^{\circ}$.

Since these results suggested that the inability of the cryptococcus to continue multiplication at $30^{\circ}$, after being transferred from $16^{\circ}$, might be caused in part by a deficiency in the amino acid synthesizing capacities of the cryptococcus, a study was made of the effect of supplementing cultures with amino acids, in the form of bacteriological peptone (Difco), yeast extract (Difco) or DL-glutamic acid, on growth of, and content of intracellular amino acids in, the cryptococcus. These sources of amino acids were added as solutions $(12 \%, \mathrm{w} / \mathrm{v} ; \mathrm{pH} 4.5)$ to cultures which had been transferred from $16^{\circ}$ to $30^{\circ}$ after $144 \mathrm{hr}$, to give a concentration in the cultures of $0.92 \%(w / v)$. The effect of adding a solution of bacteriological peptone is shown in the data in Table 1. These results show that addition of peptone to cultures of the cryptococcus maintained at $16^{\circ}$ stimulated growth to some extent, and also brought about an increase in the size of the intracellular amino acid pool. But addition of peptone did not have any detectable effect on growth of the cryptococcus in cultures 
that had been transferred to $30^{\circ}$, while the size of the intracellular amino acid pool in this organism increased only very slightly. Similar results were obtained following additions of yeast extract or glutamic acid to cultures of the cryptococcus.

Table 1. Effect of addition of peptone on growth of, and content of total intracellular amino acids in the cryptococcus at $16^{\circ}$ and $30^{\circ}$

Cultures $(6 \mathrm{ml}$.) of the cryptococcus, grown in a medium containing $2 \%(\mathrm{w} / \mathrm{v})$ glucose, were transferred from $16^{\circ}$ to $80^{\circ}$ after incubation for $144 \mathrm{hr}$.; control cultures were maintained at $16^{\circ}$. At the time of transfer, certain of these cultures received $0.5 \mathrm{ml}$. sterile $12 \%(w / v)$ solution (pH 4.5) of bacteriological peptone. At the same time, certain of the cultures maintained at $16^{\circ}$ were similarly supplemented with peptone.

\begin{tabular}{|c|c|c|c|c|c|}
\hline & \multicolumn{2}{|c|}{$\begin{array}{c}\text { Growth } \\
\left(\text { cryptococci } / \mathrm{ml}, \times 10^{7}\right)\end{array}$} & \multicolumn{2}{|c|}{$\begin{array}{c}\text { Intracellular amino acid } \\
\text { pool }\left(\mu \mathrm{g} . \mathrm{NH}_{2} / 60 \times 10^{7}\right. \\
\text { cryptococci) }\end{array}$} \\
\hline & & & & & \\
\hline $16^{\circ}$ & $80^{\circ}$ & $\begin{array}{c}\text { Nó } \\
\text { additition }\end{array}$ & $\begin{array}{l}\text { Peptone } \\
\text { added }\end{array}$ & $\begin{array}{c}\text { No } \\
\text { addition }\end{array}$ & $\begin{array}{l}\text { Peptone } \\
\text { added }\end{array}$ \\
\hline 144 & - & $2 \cdot 20$ & - & 23.5 & - \\
\hline 192 & - & 2.90 & $8 \cdot 10$ & 12.5 & $18 \cdot 4$ \\
\hline 144 & 48 & $8 \cdot 30$ & $3 \cdot 20$ & $7 \cdot 5$ & $8 \cdot 8$ \\
\hline 240 & - & $8 \cdot 50$ & 3.80 & 10.0 & 15.2 \\
\hline 144 & 96 & 8.60 & 8.50 & 4.0 & $6 \cdot 2$ \\
\hline 288 & - & $4 \cdot 10$ & $4 \cdot 50$ & $8 \cdot 4$ & $18 \cdot 1$ \\
\hline 144 & 144 & $8 \cdot 60$ & 8.50 & 8.5 & 6.7 \\
\hline
\end{tabular}

Table 2. Effect of change in incubation temperature from $16^{\circ}$ to $30^{\circ}$ on the total oxo acid content of the cryptococcus

\begin{tabular}{|c|c|c|c|}
\hline \multicolumn{2}{|c|}{ Incubation (hr.) } & \multirow{2}{*}{$\begin{array}{c}\text { Growth } \\
\text { (cryptococci } / \mathrm{ml} . \times 10^{7} \text { ) }\end{array}$} & \multirow{2}{*}{$\begin{array}{l}\text { Total intracellular } \\
\text { oxo acids } \\
\text { ( } \mu \mathrm{g} \cdot \alpha \text {-oxoglutaric } \\
\text { acid equivalent } / \\
60 \times 10^{7} \text { cryptococci) }\end{array}$} \\
\hline $16^{\circ}$ & $80^{\circ}$ & & \\
\hline 144 & - & $2 \cdot 17$ & 0.37 \\
\hline 96 & 48 & $\mathbf{2} \cdot 55$ & $0 \cdot 23$ \\
\hline 168 & - & $2 \cdot 50$ & $0 \cdot 41$ \\
\hline 120 & 48 & $2 \cdot 79$ & 0.26 \\
\hline 192 & - & 8.06 & 0.45 \\
\hline 96 & 96 & $2 \cdot 65$ & 0.12 \\
\hline 216 & 一 & $\mathbf{8 \cdot 2 0}$ & 0.48 \\
\hline 120 & 96 & $\mathbf{8 \cdot 1 0}$ & 0.09 \\
\hline
\end{tabular}
Effect of change in incubation temperature on the size of the intracellular
oxo acid pool

The results described in the previous section suggested that one reason for the failure of the cryptococcus to continue multiplication at $\mathbf{8 0 ^ { \circ }}$ after being transferred from $16^{\circ}$ was because it lacked the ability to synthesize amino acids and to accumulate these compounds from the medium. A study was therefore made of the effect of a change of incubation temperature on the total oxo acid content of the cryptococcus, since certain key amino acids are known to be synthesized from $\alpha$-oxo acids. The results of this study are summarized in Table 2. These data show that, although the total oxo acid content of the cryptococcus increased slightly during incubation at $16^{\circ}$, there was, after an initial slight increase, a steady decline in the total amounts of 
these acids in the cryptococcus from cultures that had been transferred from $16^{\circ}$ to $\mathbf{3 0}^{\circ}$. Chromatographic examination of extracts from cryptococci which had been maintained at $16^{\circ}$ and from cryptococci which had been transferred from $16^{\circ}$ to $30^{\circ}$ revealed the presence of three oxo acids which ran identically with $\alpha$-oxoglutarate, oxaloacetate and pyruvate. The pyruvic acid spot always appeared most intense, while that of oxaloacetate was least intense.

\section{Influence of tricarboxylic acid cycle intermediates on growth of the cryptococcus at $30^{\circ}$}

The data in Table 2 suggest that, at $30^{\circ}$, the cryptococcus is unable to synthesize adequate amounts of oxo acids. Accordingly, an examination was made of the effect of adding certain oxo acids and tricarboxylic acid cycle intermediates to cultures that had been transferred from $16^{\circ}$ to $30^{\circ}$ after $120 \mathrm{hr}$; ; additions were made at the time of transfer or after incubation for $72 \mathrm{hr}$. at the higher temperature. The

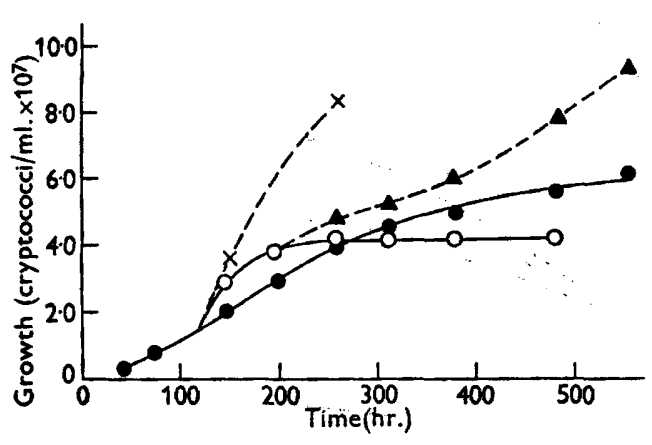

Fig. 2

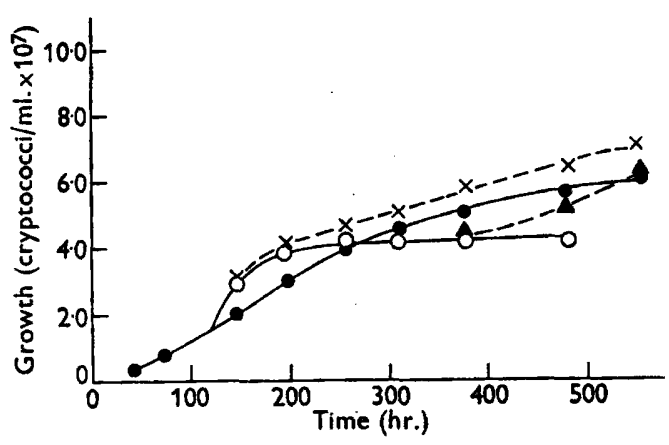

Fig. 8

Figs. 2, 3. Fffect of addition of $\alpha$-oxoglutarate (Fig, 2), and citrate (Fig. 3) on growth of the cryptococcus in cultures transferred from $16^{\circ}$ to $30^{\circ}$ after $120 \mathrm{hr}$. Cultures $(6 \mathrm{ml}$.) received $0.5 \mathrm{ml}$. of a sterile $12 \%(\mathrm{w} / \mathrm{v})$ solution $(\mathrm{pH} 4.5)$ of the potassium salt of the acid on being transferred to $30^{\circ}(x-\cdots-x)$ or after $72 \mathrm{hr}$. incubation at $30^{\circ}(\Delta-\cdots)$. Control curves show growth of the cryptococcus in cultures maintained at $16^{\circ}(O-O)$ and in cultures transferred to $30^{\circ}$ after $120 \mathrm{hr}$. at $16^{\circ}$ but which received no additions (O-O). The basal medium contained $1 \%(w / v)$ glucose.

compounds tested were pyruvic, acetic, citric, DL-isocitric, $\alpha$-oxoglutaric, succinic, fumaric, $\mathrm{L}$-malic and oxaloacetic acids. These compounds were added separately to cultures as solutions $(12 \%, \mathrm{w} / \mathrm{v} ; \mathrm{pH} 4.5)$ of their potassium or sodium salts to give a concentration of $0.92 \%(w / v)$ in the culture. Initially, each compound was tested for its ability to act as the sole carbon source in the medium at a concentration of $0.92 \%$ $(w / v)$. All, with the exception of acetate and isocitrate, were capable of supporting growth of the cryptococcus at $16^{\circ}$. However, growth at $30^{\circ}$ in cultures transferred from $16^{\circ}$ was stimulated only in cultures that had received citric, isocitric or $\alpha$-oxoglutaric acids. Addition of each of the other compounds tested, with the exception of acetate, had no detectable effect on growth of the cryptococcus at $30^{\circ}$; addition of acetate brought about an almost immediate cessation of growth. The stimulatory effect of $\alpha$-oxoglutarate was most marked when this compound was added at the time of transfer from $16^{\circ}$ to $30^{\circ}$ (Fig. 2). When the oxo acid was added after incubation for $72 \mathrm{hr}$. at $30^{\circ}$, there was a lag period before the cryptococcus began to grow 
quickly. Addition of citrate (Fig. 3) or isocitrate caused much less stimulation of growth, although there was again a lag period before the cryptococcus grew following addition of these acids to cultures which had been incubated at $30^{\circ}$ for $72 \mathrm{hr}$. There was no change in the pattern of growth when peptone, at a concentration in the culture of $0.92 \%(\mathrm{w} / \mathrm{v})$, was added together with citrate or isocitrate. Addition of succinate, fumarate, malate or oxaloacetate, in the presence or absence of peptone, not only failed to stimulate growth of the cryptococcus at $30^{\circ}$ but also had no effect on the total oxo acid content of the organism; moreover, there was no change in the

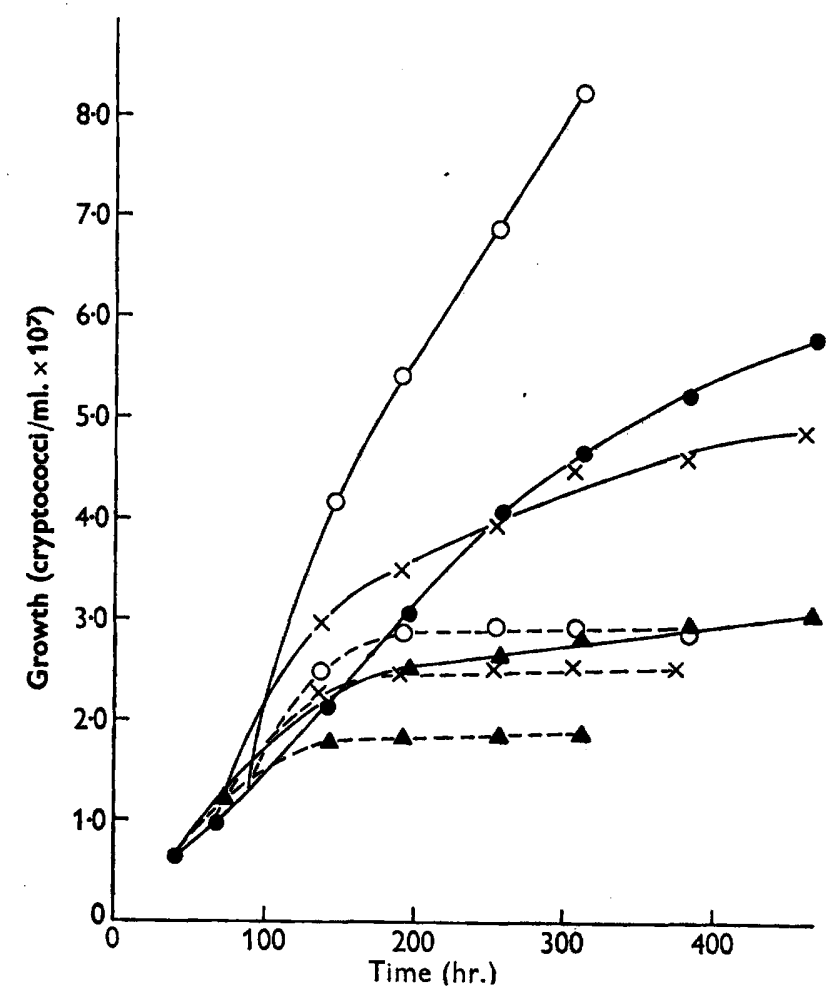

Fig. 4. Effect of addition of $\alpha$-oxoglutarate on growth of the cryptococcus in cultures transferred from $16^{\circ}$ to $30^{\circ}$ after $48 \mathrm{hr}$. ( $\left.\Delta-\Delta\right), 72 \mathrm{hr} .(x-x)$ and $96 \mathrm{hr} .(0-0)$. At the time of transfer, each of the triplicate cultures received $0.5 \mathrm{ml}$. of a sterile $12 \%$ (w/v) solution ( $\mathrm{pH} 4.5$ ) of potassium $\alpha$-oxoglutarate. Growth of control cultures which did not receive $\alpha$-oxoglutarate on being transferred to $80^{\circ}$ is shown with dotted lines. Growth of cultures maintained throughout at $16^{\circ}$ is also shown (-O).

proportions of the three oxo acids, as detected chromatographically, in extracts from cryptococci grown in media containing any one of these tricarboxylic acid cycle intermediates.

Although addition of $\alpha$-oxoglutarate, at the time of transfer, to cultures which had been incubated at $16^{\circ}$ for $120 \mathrm{hr}$., allowed the cryptococcus to continue to grow at $30^{\circ}$, freshly inoculated cultures containing $\alpha$-oxoglutarate did not grow when incubated at this temperature. A study of the effect of the time of prior incubation at $16^{\circ}$ 
on the subsequent growth at $30^{\circ}$ in the presence of $\alpha$-oxoglutarate showed that an incubation period of about $96 \mathrm{hr}$. at the lower temperature was required before addition of the oxo acid brought about a maximum stimulation of growth at $30^{\circ}$ (Fig. 4).

\section{DISCUSSION}

The results reported in this paper are concerned with the biochemical basis of only one of the two properties which distinguish obligate psychrophilic micro-organisms from mesophilic species: namely, the inability to grow at temperatures of $30^{\circ}$ and above. The data obtained show that, in a psychrophilic species of Cryptococcus, this property can be explained, in part, by the inability of the organism to synthesize adequate quantities of $\alpha$-oxoglutarate. Thus, addition of this oxo acid to cultures that had been transferred to $30^{\circ}$ after at least $96 \mathrm{hr}$. at $16^{\circ}$ brought about rapid growth of the cryptococcus at the higher temperature. Inability to synthesize $\alpha$-oxoglutarate at $30^{\circ}$ presumably explains the marked decline in the size of the amino acid pool in cryptococci transferred from $16^{\circ}$ to $30^{\circ}$ and, in particular, the rapid utilization of the glutamic acid in this pool. It is also possible that this impairment in the metabolic processes leading to synthesis of $\alpha$-oxoglutarate is accompanied by a derangement in the respiratory metabolism of the cryptococcus. In the present study, however, no attempt was made to measure the respiratory activity of the cryptococcus at various temperatures. But the finding that, at $30^{\circ}$, the cryptococcus was apparently unable to assimilate appreciable quantities of exogenous amino acids, even when these compounds were deficient in the organisms, suggests that, at this temperature, the cryptococcus may be incapable of furnishing the supply of energy needed for the uptake of these nutrients.

From the data available, it is not possible, however, to state precisely the location of the metabolic lesions that are responsible for the increased nutritional demand for $\alpha$-oxoglutarate at $30^{\circ}$. The results of studies on the uptake of tricarboxylic acid cycle intermediates and related compounds by micro-organisms are frequently not easy to interpret because of the existence of permeability barriers which prevent free access of externally added substrates to intracellular enzyme systems (Barnett \& Kornberg, 1960). But, since only two of the intermediates tested (acetate, isocitrate) were unable to serve as sole carbon source in the medium, it must be presumed that each of the other compounds tested can enter the cryptococci; it would seem too that isocitrate can be assimilated in glucose-containing media. Since both citrate and isocitrate are capable of satisfying the increased nutritional demand at $30^{\circ}$, albeit more slowly than $\alpha$-oxoglutarate, it might be assumed that the metabolic lesions responsible for this demand are in the pathway between glucose and citrate. It is possible that certain of the reactions involved in the conversion of glucose to pyruvate are impaired at $30^{\circ}$. But, since addition of pyruvate to cultures transferred from $16^{\circ}$ to $30^{\circ}$ does not lead to any increase in growth at the higher temperature, it would seem likely that at least one of the lesions lies among the reactions involved in the conversion of pyruvate to citrate.

Exogenous $\alpha$-oxoglutarate is presumably oxidized to succinate by the cryptococcus growing at $30^{\circ}$, but, from the data available, it is not possible to state whether the succinate so formed is oxidized further. However, the provision of exogenous sources of succinate and of intermediates formed from succinate (fumarate, malate, 
oxaloacetate), in the presence or absence of amino acids, did not enable the cryptococcus to grow at $30^{\circ}$. This suggests that incubation at this temperature may result in the formation of metabolic lesions among the reactions involved in the transformation of these tricarboxylic acid cycle intermediates. Support for this view comes from the finding that there was no change in the proportions of the three oxo acids in extracts from cryptococci grown in media containing these tricarboxylic acid cycle intermediates.

At least two theories have been put forward to explain the low maximum temperature of obligate psychrophilic micro-organisms. One of these postulates the existence of exceptionally thermolabile enzymes in psychrophilic micro-organisms, while the other attempts to explain the inability of these organisms to grow at higher temperatures by assuming that, at these temperatures, the cells synthesize or accumulate a metabolic poison. Since addition of $\alpha$-oxoglutarate to cultures of the cryptococcus which had been transferred from $16^{\circ}$ to $30^{\circ}$ brought about an almost immediate increase in the rate of growth at $30^{\circ}$, it seems unlikely that, in this organism, the low maximum temperature is a result of the accumulation of a metabolic poison. Further evidence to support this view comes from the finding (unpublished observations) that extracts from cryptococci which had been grown at $16^{\circ}$ and then transferred to $30^{\circ}$ were not capable of inhibiting growth of the organism at $16^{\circ}$. One is led to conclude, therefore, that the temperature-sensitive character of this psychrophil is probably explained by the presence of certain exceptionally thermolabile enzymes. Such enzymes have not been reported in psychrophils to date (Ingraham \& Bailey, 1959); they have, however, been found in mutant strains of certain mesophilic micro-organisms (Horowitz \& Fling, 1956; Maas \& Davis, 1952), and there is also evidence to suggest that certain enzymes in wild-type mesophils may have relatively low temperature maxima (Lichstein \& Begue, 1960; Sherman, 1959) and that these enzymes may form the basis of the temperature-sensitive system that is responsible for the onset of synchronous growth following repeated changes in incubation temperature (Eichel, 1956).

The finding that the addition of $\alpha$-oxoglutarate, citrate or isocitrate to freshly inoculated cultures of the cryptococcus did not enable it to grow at $30^{\circ}$ indicates the presence of other abnormally temperature-sensitive metabolic processes in addition to those involved in $\alpha$-oxoglutarate synthesis. Apparently, however, the thermolability of these processes is no longer growth-limiting after the cryptococcus has been incubated for $96 \mathrm{hr}$. at $16^{\circ}$. It is possible that these other temperature-sensitive processes may be concerned with the synthesis of certain enzymes during the early stages of growth; in this connexion, it is interesting to note that the process of enzyme induction in various micro-organisms has been shown to be particularly heatsensitive (Knox, 1953).

\section{REFERENCES}

Ahmad, F., Rose, A. H. \& Garg, N. K. (1961). Effect of biotin deficiency on the synthesis of nucleic acids and protein by Saccharomyces cerevisiae. J. gen. Microbiol. 24, 69.

BarnetT, J. A. \& Kornberg, H. L. (1960). The utilization by yeasts of acids of the tricarboxylic acid cycle. J. gen. Microbiol. 23, 65.

Brown, A. D. (1957). Some general properties of a psychrophilic pseudomonad; the effects of temperature on some of these properties and the utilization of glucose by this organism and Pseudomonas aeruginosa. J. gen. Microbiol. 18, 640. 


\section{Biochemistry of a psychrophilic cryptococcus}

EICHeL, H. J. (1956). Respiratory enzyme studies in Tetrahymena pyriformis. II. Reduced diphosphopyridine nucleotide oxidase and reduced diphosphopyridine nucleotide cytochrome c reductase. J. biol. Chem. 222, 121.

Frnedemann, T. E. \& Haugen, G. E. (1943). Pyruvic acid. II. The determination of keto acids in blood and urine. J. biol. Chem. 147, 415 .

Hagen, P-O. \& Rose, A. H. (1961). A psychrophilic cryptococcus. Canad. J. Microbiol. 7, 287.

Horowitz, N. H. \& Fuing, M. (1956). Tyrosinase production by a heterocaryon of Neurospora. Proc. nat. Acad. Sci., Wash., $42,498$.

INGraham, J. L. \& BaILEy, G. F. (1959). A comparative study of the effect of temperature on the metabolism of psychrophilic and mesophilic bacteria. J. Bact. 77, 609.

Krox, R. (1953). The effect of temperature on enzymic adaptation, growth and drug resistance. In Adaptation in Micro-organisms. Symp. Soc. gen. Microbiol. 3, 184.

LiChSTEIN, H. C. \& BEGUE, W. J. (1960). Increased nutritional requirements of Saccharomyces cerevisiae as a result of incubation at $38^{\circ}$ C. Proc. Soc. exp. Biol., N.Y. 105, 500.

MaAs, W. K. \& Davis, B. D. (1952). Production of an altered pantothenate-synthesizing enzyme by a temperature-sensitive mutant of Escherichia coli. Proc. Soc. exp. Biol., N.Y. 38, 785.

MARKHAM, R. (1942). A steam distillation apparatus suitable for micro-Kjeldahl analysis. Biochem. J. 36, 790.

Meister, A. \& Abendschein, P. A. (1956). Chromatography of alpha-keto acid 2,4-dinitrophenylhydrazones and their hydrogenation products. Analyt. Chem. 28, 171.

Mruler, L. \& Hovghton, J. A. (1945). The micro-Kjeldahl determination of the nitrogen content of amino acids and proteins. J. biol. Chem. 159, 373.

NorthaM, B. E. \& NonRIs, F. W. (1951). Growth requirements of Schizosaccharomyces octosporus, a yeast exacting towards adenine. J. gen. Microbiol. 19, 146.

Rose, A. H. \& Nickerson, W. J. (1956). Secretion of nicotinic acid by biotin-dependent yeasts. J. Bact. 72, 324.

Sherman, F. (1959). The effects of elevated temperatures on yeast. I. Nutrient requirements for growth at elevated temperatures. J. cell. comp. Physiol. 54, 29.

Smith, A. M. \& AGrzA, A. H. (1957). The determination of amino acids colorimetrically by the ninhydrin reaction. Analyst, 76, 623. 